\title{
Differentially expressed serum proteins associated with calcium regulation and hypocalcemia in dairy cows
}

\author{
Shi Shu', Yunlong Bai', Gang Wang ${ }^{1}$, Xinhuan Xiao', Ziling Fan', Jiang Zhang ${ }^{1}$, Chang Zhao', \\ Yang Zhao ${ }^{1}$, Cheng Xia ${ }^{1, *}$, and Hongyou Zhang ${ }^{1}$
}

\begin{abstract}
* Corresponding Author: Cheng Xia Tel: +86-4596819207, Fax: +86-4596819207, E-mail: xcwlxyf2014@163.com
\end{abstract}

${ }^{1}$ College of Animal Science and Veterinary Medicine, Heilongjiang Bayi Agricultural University, Daqing 163319, China

Submitted Aug 18, 2016; Revised Sept 22, 2016; Accepted Nov 2, 2016
Objective: Hypocalcemia is an important metabolic disease of dairy cows during the transition period, although the effect of hypocalcemia on biological function in dairy cows remains unknown.

Methods: In this study, proteomic, mass spectrum, bioinformatics and western blotting were employed to identify differentially expressed proteins related to serum Ca concentration. Serum samples from dairy cows were collected at three time points: 3 rd days before calving (day -3 ), the day of calving (day 0$)$, and 3 rd days after calving $($ day +3$)$. According to the Ca concentration on day 0 , a total of 27 dairy cows were assigned to one of three groups (clinical, subclinical, and healthy). Samples collected on day -3 were used for discovery of differentially expressed proteins, which were separated and identified via proteomic analysis and mass spectrometry. Bioinformatics analysis was performed to determine the function of the identified proteins (gene ontology and pathway analysis). The differentially expressed proteins were verified by western blot analysis.

Results: There were 57 differential spots separated and eight different proteins were identified. Vitamin D-binding protein precursor (group-specific component, GC), alpha-2-macroglobulin (A2M) protein, and apolipoprotein A-IV were related to hypocalcemia by bioinformatics analysis. Due to its specific expression (up-regulated in clinical hypocalcemia and down-regulated in subclinical hypocalcemia), A2M was selected for validation. The results were consistent with those of proteomic analysis.

Conclusion: A2M was as an early detection index for distinguishing clinical and subclinical hypocalcemia. The possible pathogenesis of clinical hypocalcemia caused by GC and apolipoprotein A-IV was speculated. The down-regulated expression of GC was a probable cause of the decrease in calcium concentration.

Keywords: Dairy Cows; Hypocalcemia; Proteomic; Bioinformatics

\section{INTRODUCTION}

Hypocalcemia is an important nutritional metabolic disease of dairy cows that occurs from 0 to 3 days after calving and is characterized by a reduction in serum calcium (Ca) concentration that does not return to normal for several days. Previous studies have reported that the incidence of hypocalcemia in dairy cows is 3.45\% in North America, 6.17\% in Europe, and 3.5\% in Australia [1].

Hypocalcemia can be divided into two stages: clinical hypocalcemia $(\mathrm{CH})$ and subclinical hypocalcemia (SH). According to the Merck Veterinary Manual (http://www.merckmanuals. $\mathrm{com} / \mathrm{vet} /$ ), the normal serum Ca concentration in the cow is 2.25 to $2.5 \mathrm{mmol} / \mathrm{L}$, while the Ca concentrations in $\mathrm{CH}$ and $\mathrm{SH}$ are defined as 0.5 to 1.75 and $<2.0 \mathrm{mmol} / \mathrm{L}$, respectively. Hypocalcemia reduces the ability of immune cells to respond to stimuli [2], thus contributing to the 
onset of infection, such as mastitis. Furthermore, hypocalcemia reduces smooth muscle contraction, leading to reduced rumen and abomasal motility, resulting in abomasal displacement and reduced feed intake. The effects of hypocalcemia on muscle contraction prevent efficient teat closure, which also contributes to the onset of mastitis [3]. It is well known that $\mathrm{Ca}$ concentration is the "gold standard" for the diagnosis of hypocalcemia at 0 to 3 days after calving. Upon diagnosis, cows will rapidly succumb to hypocalcemia, especially $\mathrm{CH}$. In fact, many proteins are known to affect Ca regulation in dairy cows. Shu and Wang reported 12 differentially expressed proteins related to $\mathrm{CH}$ and $\mathrm{SH}$ by surface-enhanced laser desorption/ionization time-of-flight mass spectrometry $[4,5]$.

Proteomics is a relatively new technology in bovine research and is widely used in other areas of research, such as human cancers [6], plant science [7], immunology, and parasitology. Two-dimensional gel electrophoresis (2-DE) coupled with mass spectrometry offers a comprehensive proteomic approach [8], while fluorescence two-dimensional differential gel electrophoresis (2D-DIGE) technology adds a quantitative component to conventional 2-DE analyses, allowing for direct comparison of changes in protein abundance across multiple samples simultaneously, with statistical confidence and without interference due to gel-togel variation $[9,10]$. Matrix-assisted laser desorption/ionizationtime of flight mass spectrometry (MALDI-TOF-MS) is often used to identify proteins discovered by 2D-DIGE.

Serum samples from healthy dairy cows and those with $\mathrm{CH}$ and SH were analyzed by 2D-DIGE/MALDI-TOF-MS combined with bioinformatics to identify differentially expressed proteins that affect serum Ca regulation and to elucidate the cause of the reduction in serum Ca concentration after calving and determine why the Ca concentration is not restored to normal for several days after calving.

\section{MATERIALS AND METHODS}

\section{Experimental animals}

All experimental animals were obtained from an intensive dairy farm in accordance with the requirements of the Veterinary Medical Ethical Committee of the Local Agricultural Department of Mishan, Heilongiiang province, China. All experimental animals were maintained in accordance with the International Guiding Principles for Biomedical Research Involving Animals. All cows were fed a total mixed ration (TMR) during the prepartum period, which consisted of $9 \mathrm{~kg}$ of concentrated feed, $17 \mathrm{~kg}$ of silage maize, $4 \mathrm{~kg}$ of hay, and $400 \mathrm{~g}$ of fat. The nutritional analysis of the TMR was $55.60 \%$ dry matter, $16 \%$ crude protein, $5.60 \%$ fat, $39.10 \%$ neutral detergent fiber, $20.30 \%$ acid detergent fiber, and $1.75 \mathrm{mcal} /$ net energy for lactation, $180 \mathrm{~g}$ of Ca, $116 \mathrm{~g}$ of phosphorus.

\section{Grouping}

Blood samples were collected from randomly selected Holstein cows at three time points: 3 rd day before calving (day -3$)$, day of calving (day 0 ), and 3rd day after calving (day +3 ). None of the cows showed any clinical symptoms on day -3 and diseases other than hypocalcemia on day 0 were excluded. The cows were assigned to one of three groups based on serum Ca concentration on day 0: the $\mathrm{CH}$ group $(\mathrm{n}=9)$, obvious clinical symptoms of hypocalcemia and $\mathrm{Ca}$ concentration of $<1.80 \mathrm{mmol} / \mathrm{L}$; the $\mathrm{SH}$ group $(\mathrm{n}=9)$, no clinical symptoms of hypocalcemia and $\mathrm{Ca}$ concentrations of 1.80 to $2.00 \mathrm{mmol} / \mathrm{L}$; and a control (C) group $(\mathrm{n}=9)$, no clinical symptoms of hypocalcemia and Ca concentrations of 2.00 to $3.00 \mathrm{mmol} / \mathrm{L}$.

\section{Blood parameter analysis}

Blood samples $(10 \mathrm{~mL})$ from all tested cows were collected from the caudal vein at three time points in accordance with the International Guiding Principles for Biomedical Research Involving Animals. The samples were centrifuged immediately at 4,000 g for $10 \mathrm{~min}$. Then, the serum fraction was frozen in liquid nitrogen and stored at $-80^{\circ} \mathrm{C}$ until subsequent analyses. The serum Ca concentration was detected using a commercial kit (651564-01; Roche Diagnostics, Mannheim, Germany) with an automatic biochemical analyzer (Modular DPP; Roche Diagnostics, Germany). The serum Ca concentrations at the three time points are shown Figure 1 and group values are shown in Supplementary Table S1.

To reduce individual differences, every sample for 2D-DIGE was obtained from serum samples of three animals. The test design is depicted in Table 1 and the study strategy is shown in Supplementary Table S2.

\section{Protein processing}

Serum samples were thawed at room temperature and pooled in accordance with the study design. Protein concentrations were measured using the Bradford protein assay. Lysis buffer and 3.5

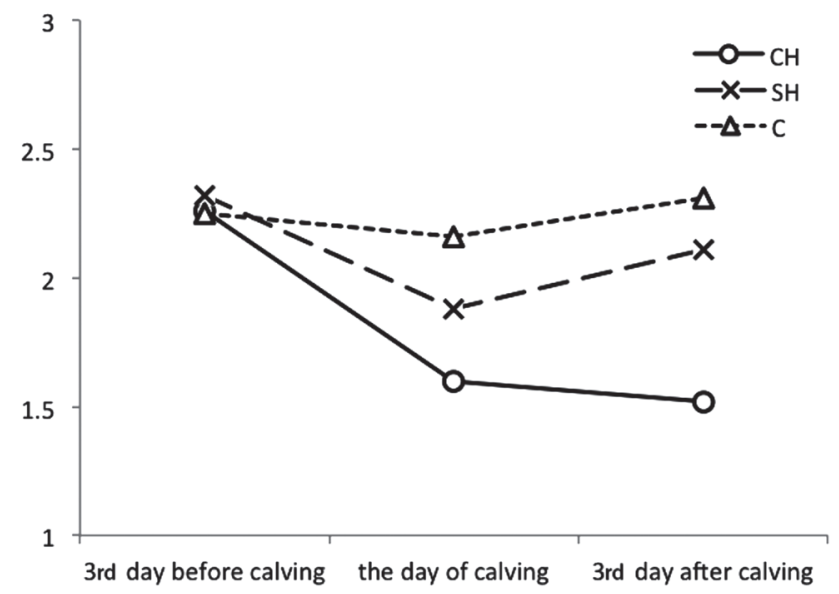

Figure 1. Ca concentration at three time points. The mean Ca concentration in each group at three time points. 
Table 1. The design of fluorescence-labeled samples"

\begin{tabular}{lccc}
\hline \multirow{2}{*}{ Gel-ID } & \multicolumn{3}{c}{ Label $^{2)}$} \\
\cline { 2 - 4 } & Cy2 & Cy3 & Cy5 \\
\hline Gel 1 & Interior label & $\mathrm{CH} 1$ & $\mathrm{SH} 1$ \\
Gel 2 & Interior label & $\mathrm{SH} 2$ & $\mathrm{C} 1$ \\
Gel 3 & Interior label & $\mathrm{C} 2$ & $\mathrm{CH} 2$ \\
Gel 4 & Interior label & $\mathrm{CH} 3$ & $\mathrm{C} 3$ \\
Gel 5 & Interior label & $\mathrm{SH} 3$ & $\mathrm{CH} 2$ \\
\hline
\end{tabular}

1) The regulation of labeled is that sample of every group was not labeled only one kind fluorescence.

2) "Interior label" is pooled all samples for reducing the individual difference. " $\mathrm{CH} 1$, $\mathrm{CH} 2, \mathrm{CH}_{3}$ " are three samples in clinical hypocalcemia group. "SH1, $\mathrm{SH} 2, \mathrm{SH}^{\prime}$ " are three samples in subclinical hypocalcemia group. "C1, C2, C3" are three samples in control group.

$\mathrm{mg} / \mathrm{mL}$ of bovine serum albumin (BSA) at a ratio of $1: 3$ with $\mathrm{ddH}_{2} \mathrm{O}$ at a ratio of $1: 9$ with the sample were added to a test tube. A 5- $\mu \mathrm{L}$ aliquot of the sample, which was diluted according to the above method, was homogenized in BSA (standard protein buffer) and $875 \mu \mathrm{L}$ of protein assay buffer (Bio-Rad Laboratories, Inc., Hercules, CA, USA). Protein concentrations were quantified spectrophotometrically at $595 \mathrm{~nm}$ with BSA as a standard.

The abundance of albumin and immunoglobulins are varied in serum, and can account for up to $95 \%$ of proteins in serum. To increase resolution of the gels, highly abundant proteins were extracted and purified using a protein purification kit (GE Healthcare, Buckinghamshire, UK), while impurities were removed using a 3-kD hyperfiltration tube (UFC800396; Merck Millipore, Billerica, MA, USA), and then centrifuged at 10,000 $\mathrm{g}$ for 30 min. All protein concentrations were quantified twice according to the above method.

\section{Fluorescent labelling of proteins}

$\mathrm{NaOH}(50 \mathrm{mmol} / \mathrm{L})$ was added to the samples to adjust the $\mathrm{pH}$ to 8.5 and lysis buffer was added to adjust the concentration to $5 \mathrm{mg} / \mathrm{mL}$. The interior label was a mixed liquor of all nine samples and $400 \mathrm{pmol} \mathrm{Cy} 2$ fluorescent label was added to every $50 \mu \mathrm{g}$ of protein in the interior label. The samples were randomly labeled with $\mathrm{Cy} 3$ and $\mathrm{Cy} 5$. The $\mathrm{CH} 1$ sample was added twice to the different gels because of the odd number of total samples. This design was chosen to reduce the occurrence of technical errors and increase replication.

Cy3- and Cy5-labeled samples $(50 \mu \mathrm{L})$ were mixed with the interior label and then two-fold buffer ( $7 \mathrm{M}$ urea, $2 \mathrm{M}$ thiourea, 4\% CHAPS (3-[\{3-Cholamidopropyl\} dimethylammonio] propanesulfonic acid), 1\% Bio-Lyte, $\mathrm{pH} 3$ to 10, $20 \mathrm{mg} / \mathrm{mL}$ dithiothreitol (DTT) and hydration buffer (7 M urea, $2 \mathrm{M}$ thiourea, $4 \%$ CHAPS, $0.5 \%$ Bio-Lyte, $10 \mathrm{mg} / \mathrm{mL}$ DTT) were added for a final volume of $410 \mu \mathrm{L}$.

\section{Two-dimensional gel electrophoresis}

Immobiline DryStrips (length, $18 \mathrm{~cm}$; GE Healthcare, UK), containing immobilized ampholytes forming a linear $\mathrm{pH}$ gradi- ent of 4 to 7, were used for isoelectric focusing (IEF) in the first dimension. The strips were rehydrated in $100 \mu \mathrm{L}$ of a buffer containing $7 \mathrm{mmol} / \mathrm{L}$ urea, $2 \mathrm{mmol} / \mathrm{L}$ thiourea, $4 \%$ CHAPS, 30 $\mathrm{mmol} / \mathrm{L}$ Tris buffer, and deionized water. Immobilized $\mathrm{pH}$ gradient (IPG) rehydration buffer contained $4.5 \mathrm{mg}$ of $1 \% \mathrm{DDT}, 4.5 \mu \mathrm{L}$ of $40 \%$ ampholyte, and trace amounts of bromophenol blue. The samples were applied to the strips following a cup loading protocol and IEF was performed at room temperature using the IPGPhor IEF system (Amersham Biosciences, Amersham, $\mathrm{UK}$ ) at $50 \mathrm{~V}$ per strip for $13 \mathrm{~h}$, according to the following program: fast gradient at $200 \mathrm{~V}$ for $30 \mathrm{~min}$ (to remove impurities), linear gradient at $1,000 \mathrm{~V}$ for $6 \mathrm{~h}$, focusing at $10,000 \mathrm{~V}$ for 60,000 $\mathrm{vh}$, and fast gradient at $500 \mathrm{~V}$ to the end of the run.

After IEF, the IPG strips were incubated in equilibration buffer I ( $6 \mathrm{~mol} / \mathrm{L}$ urea, $20 \%$ glycerol, $2 \%$ sodium dodecyl sulfate (SDS), $0.375 \mathrm{~mol} / \mathrm{L}$ Tris-HCl, $0.1 \mathrm{~g}$ DDT) while shaking for $15 \mathrm{~min}$, and then in equilibration buffer II (buffer I in which DTT was replaced by $0.4 \mathrm{~g}$ iodoacetamide) for a further $15 \mathrm{~min}$. Thereafter, the strips were individually applied to the surface of a vertical $12 \%$ polyacrylamide gel and sealed with $0.5 \%$ agarose dissolved in electrophoresis buffer (3 g Tris-alkali, $14.4 \mathrm{~g}$ of glycerol, $0.1 \%$ SDS) with traces of bromophenol blue. SDS-polyacrylamide gel electrophoresis (PAGE) Broad Range or All Blue Precision Plus Protein (Bio-Rad Laboratories, Inc., USA) molecular weight standards were loaded at each end of the strip. Second-dimension electrophoresis was performed using an EttanDALT II gel at a constant gain of $30 \mathrm{~V}$ for $60 \mathrm{~min}$, then $80 \mathrm{~V}$ for $16 \mathrm{~h}$.

\section{Gel scanning and analysis}

Following electrophoresis, signals from the three fluorophores in each gel were sequentially scanned using a Typhoon 9410 fluorescence imager (GE Healthcare, UK). The corresponding excitation and emission wavelengths for Cy 3 and Cy 5 were 532 and $580 \mathrm{~nm}$, and 633 and $670 \mathrm{~nm}$, respectively. Cy2 images were obtained at wavelengths of 488 and $520 \mathrm{~nm}$. The DeCyder (V6.5) was used for analysis of the DIGE gel to determine differences in protein content. The $t$-test was used to identify significant differences in protein expression. A probability $(p)$ value of $\leq 0.05$ and an increase in expression of $>1.5$-fold were considered statistically significant.

\section{Mass spectrometry analyses and database search for protein identification}

According to the results of the second protein quantification, the preparation gel, which was used for MS, was used for all samples according to the above-mentioned method. The analysis gel, which was used to determine differences in protein expression, was used to compare the preparations to ensure the places of proteins exhibiting differences in expression profiles. Then, spots containing proteins were carefully excised using a scalpel. After freeze-drying, the spots were mixed with trypsin solution and then subjected to enzymolysis at $37^{\circ} \mathrm{C}$ in a water bath for 
$16 \mathrm{~h}$. Before MS analysis, peptides were extracted by the addition of $5 \%$ trifluoroacetic acid (TFA) solution. Then, $0.5 \mu \mathrm{L}$ of each peptide sample was placed on target of the mass spectrograph. After addition of $5 \mathrm{mg} / \mathrm{mL}$ of matrix solution ( $\alpha$-cyan-4-hydroxycinnamic acid, $0.1 \%$ TFA, $50 \%$ acetonitrile), the peptide samples were analyzed by MALDI-TOF MS using an ABI-4800 mass spectrometer (Applied Biosystems, Foster City, CA, USA) under the following parameters: scanning mode, reflection-type; range, 700 to 4,000 Da; laser energy of full scan, 5,000; second scan, 5,500 . All proteins were identified by a search of the National Center for Biotechnology Information (NCBI) database.

\section{Bioinformatics analysis}

Gene ontology (GO) analysis is an important analytical method in bioinformatics software for high-throughput data. Cytoscape (http://www.cytoscape.org/) is an open source software platform for analysis of high-throughput data. The many plugins with Cytoscape are used for GO analysis and prediction of protein structure, and so on. In this study, the Bin/GO tool, a plugin of Cytoscape (version 2.8.3), was used for GO analyses.

All identified proteins were used for pathway analysis with the Kyoto Encyclopedia of Genes and Genomes (KEGG) database (http://www.genome.jp/kegg/).

\section{Western blot analysis}

The MS results showed that expression of the alpha-2-macroglobulin (A2M) protein was up-regulated in the $\mathrm{CH}$ group and down-regulated in the $\mathrm{SH}$ group, as compared with the $\mathrm{C}$ group. To verify the results of 2D-DIGE/MALDI-TOF-MS, differentially expressed proteins were chosen for western blot (WB) analysis using rabbit anti-A2M antibody (bs-9505R; Bioss, Inc., Woburn, MA, USA).

Crude serum proteins from three groups ( $\mathrm{CH}$ group, $\mathrm{n}=3$; $\mathrm{SH}$ group, $\mathrm{n}=2$; $\mathrm{C}$ group, $\mathrm{n}=3$ ) at day -3 before calving were used for WB analysis. Equal amounts of proteins were separated by $5 \%$ to $20 \%$ SDS-PAGE and transferred to polyvinylidene fluoride membranes. After blocking with 5\% skim milk powder for $2 \mathrm{~h}$ at $37^{\circ} \mathrm{C}$, target proteins were incubated with primary antibodies for $2 \mathrm{~h}$ while shaking overnight at $4^{\circ} \mathrm{C}$. Then, the membranes were incubated with secondary antibodies overnight at $4^{\circ} \mathrm{C}$. Afterward, the membranes were dried to form a gel for scanning. The A2M protein content of the three groups was analyzed to verify relative expression levels.

\section{RESULTS}

Change in Ca concentrations from before calving to after The Ca concentrations of the samples are shown in Figure 1. All data are provided in Supplementary Table S1. The Ca concentrations of all three groups were decreased on day 0 , and there were no significant difference on day -3 . Although the Ca concentrations of three groups were decreased on day 0 , that of the
C group was still in the normal range. The Ca concentration in the $\mathrm{C}$ group was restored to a normal range on day +3 , but not the other two groups, especially the $\mathrm{CH}$ group.

\section{Analysis of differential protein expression}

A representative fluorescent image is shown in Figure 2. All images are provided in Supplementary Table S3. Fifty-seven protein spots were separated. Each of these protein spots was significantly different between at least two groups (1.5-fold difference in abundance; $\mathrm{p}<0.05)$. Twenty-seven spots were selected for MALDITOF-MS, each spot on the gel was required not to be connected to any other spot, and the blot was clear and complete.

\section{Mass spectrometry identification of differentially expressed proteins}

Thirteen peptide mass fingerprints (PMFs) of 27 spots were obtained after MALDI-TOF-MS identification. The NCBI database was searched to identify the 13 PMFs to confirm the identification of the proteins. Of the $13 \mathrm{PMFs}$, eight different proteins were identified.

The results of MS analysis are shown in Table 2. The eight differentially expressed proteins included third party data (TPA): vitamin D-binding protein precursor (GC), complement $\mathrm{C} 4$ precursor (C4), paraoxonase 1 (PON1), A2M, endopin 1 (EN1), TPA: apolipoprotein A-IV precursor (APOA4), alpha-1-antitrypsin, and haptoglobin (HP).

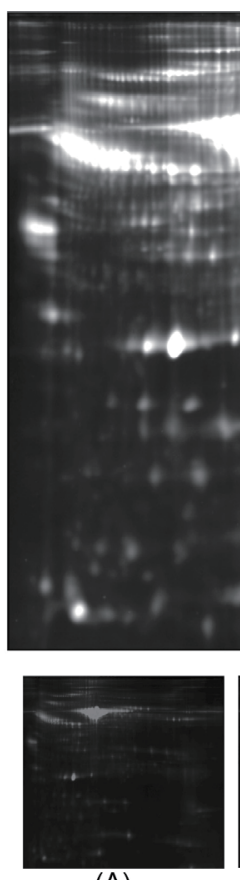

(A)



(B)



(C)
Figure 2. Two-dimensional differential gel electrophoresis (2D-DIGE) fluorescence image of one pair of $\mathrm{CH}$ and $\mathrm{C}$ samples with interior labels. (A) pooled interior label with Cy2. (B) MF labeled with Cy3. (C) C labeled with Cy5. The three pictures below: Individual channels of $\mathrm{Cy2}, \mathrm{Cy} 3$, and $\mathrm{Cy} 5$. 
Table 2. Identification of 16 differentially expressed proteins expressed among the three groups by mass spectrometry

\begin{tabular}{|c|c|c|c|c|c|c|c|c|c|}
\hline No. & Spots No. & NCBI_ID & Name of proteins & Score & Molecular mass & Abbreviation & $\mathrm{CH} / \mathrm{C}^{1 / 2)}$ & $\mathrm{SH} / \mathrm{C}$ & $\mathrm{CH} / \mathrm{SH}$ \\
\hline 1 & 1062 & gi|296486435 & TPA: vitamin D-binding protein precursor (Bos taurus) & 253 & 53321 & GC & $\downarrow$ & - & $\downarrow$ \\
\hline 2 & 630 & gi|262050656 & complement C4 precursor (Bos taurus) & 117 & 192676 & C4 & - & $\downarrow$ & - \\
\hline 3 & 1082 & gi|86826758 & Paraoxonase 1 (Bos taurus) & 75 & 39816 & PON1 & $\downarrow$ & - & $\downarrow$ \\
\hline 4 & 483 & gi|157743038 & A2M protein (Bos taurus) & 543 & 167470 & $\mathrm{~A} 2 \mathrm{M}$ & $\uparrow$ & $\downarrow$ & - \\
\hline 5 & 616 & gi|157743038 & A2M protein (Bos taurus) & 216 & 167470 & & & & \\
\hline 6 & 181 & gi|28077107 & endopin 1 (Bos taurus) & 273 & 46175 & EN1 & - & $\downarrow$ & $\uparrow$ \\
\hline 7 & 805 & gi|28077107 & endopin 1 (Bos taurus) & 277 & 46175 & & & & \\
\hline 8 & 1083 & gi|296480272 & TPA: apolipoprotein A-IV precursor (Bos Taurus) & 169 & 42963 & APOA4 & $\downarrow$ & - & $\downarrow$ \\
\hline 9 & 1131 & gi|296480272 & TPA: apolipoprotein A-IV precursor (Bos taurus) & 92 & 42963 & & & & \\
\hline 10 & 1081 & gi|42 & alpha-1-antitrypsin (Bos taurus) & 73 & 46075 & AAT & $\downarrow$ & - & $\downarrow$ \\
\hline 11 & 1087 & gi|42 & alpha-1-antitrypsin (Bos taurus) & 68 & 46075 & & & & \\
\hline 12 & 1318 & gi|83638561 & Haptoglobin (Bos taurus) & 81 & 44831 & HP & - & $\downarrow$ & - \\
\hline 13 & 1357 & gi|83638561 & Haptoglobin (Bos taurus) & 204 & 44831 & & & & \\
\hline
\end{tabular}

") $\mathrm{CH}$, clinical hypocalcemia group; $\mathrm{SH}$, subclinical hypocalcemia group; $\mathrm{C}$, healthy group.

2) $\uparrow$, up-regulation; $\downarrow$, down-regulation; -, no change.

\section{Bioinformatics analysis of differentially expressed proteins}

Gene ontology analysis: All differentially expressed proteins were analyzed using the BinGO plugin of the Cytoscape software. As shown in Supplementary Table S4, there were 150 and 24 annotations to the molecular function and biological process, respectively. Considering that a given protein can be attributed to several functions and/or processes, the annotations of biological processes and molecular functions were filtrated, which were related with hypocalcemia (Figure 3). "Steroid metabolic process", and "Vitamin D metabolic process" were the most represented biological processes. "Vitamin D binding", "Vitamin transporter activity", and "Protein binding" were the most represented molecular functions.

Pathway analysis: The KEGG Pathway database was used to search for all differentially expressed proteins. Four proteins, A2M,

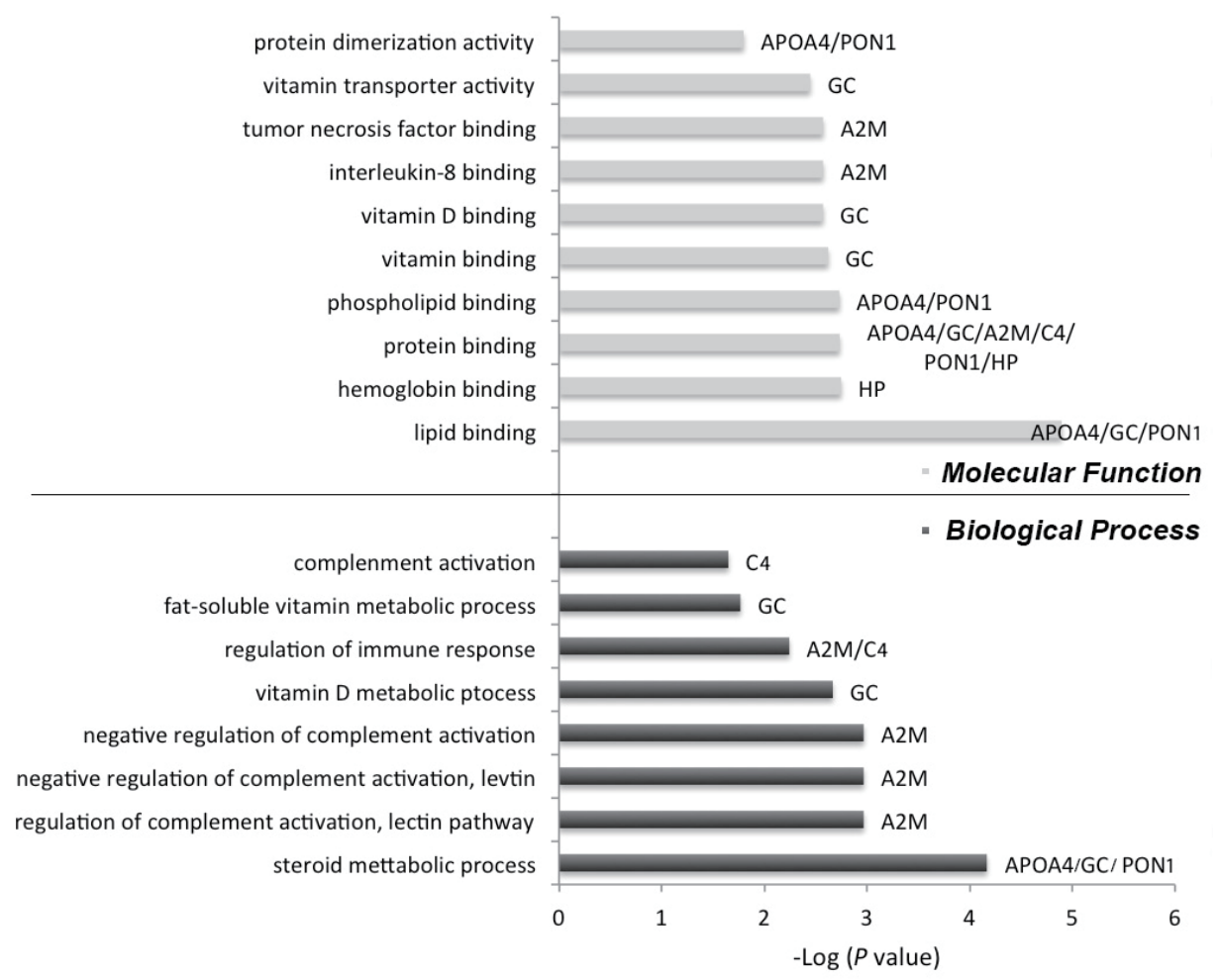

Figure 3. Gene ontology analysis. The abscissa was the $-\log ^{(p \text { value) }}$ to shown the significance between proteins and annotation. The ordinate was the annotation of molecular function (above) and biological process (below). Protein abbreviations are included in the bar graph. APOA4, apolipoprotein A-IV; PON1, Paraoxonase 1; GC, vitamin D-binding protein; A2M, A2M protein; C4, complement C4; HP, haptoglobin. 
GC, C4, and APOA4, were identified in five pathways which may be related with hypocalcemia, including the "Endocrine and other factor-regulated Ca reabsorption" (ID: 04961), "Mineral absorption" (ID: 04978), "Complement and coagulation cascades" (ID: 04611), "Fat digestion and absorption" (ID: 04975) and "Vitamin digestion and absorption" (ID: 04977) (Table 3).

Since so many pathways were found related to different proteins, all results were analyzed, filtered, and integrated. An integrated pathway to explain the relationship between the differentially expressed proteins and serum Ca regulation is shown in Figure 4. In summary, GC is an important factor in many pathways. GC specifically binds with vitamin $\mathrm{D}_{3}\left(\mathrm{VD}_{3}\right)$ in small intestinal epithelial cell and distal convoluted tubular (DCT) cells, and then promotes $\mathrm{Ca}^{2+}$ binding with the Ca-binding protein (CBP) in order to transfer $\mathrm{Ca}^{2+}$ to the blood. In addition, if there is an insufficient amount of GC specific binding with $\mathrm{VD}_{3}$, in small intestinal epithelial cells, $\mathrm{VD}_{3}$ with $\mathrm{APOA} 4$ enter the chylomicron, then the chylomicron is exocytosed to the extracellular space and finally enters the blood via lymph transfer.

Western blot analysis
Table 3. Pathway analysis

\begin{tabular}{lllc}
\hline No. & Map ID. & Name of map & Proteins $^{1)}$ \\
\hline 1 & 04961 & $\begin{array}{c}\text { Endocrine and other factor-regulated } \\
\text { calcium reabsorption }\end{array}$ & GC \\
2 & 04978 & Mineral absorption & GC \\
3 & 04610 & Complement and coagulation cascades & A2M/C4 \\
4 & 04975 & Fat digestion and absorption & APOA4 \\
5 & 04977 & Vitamin digestion and absorption & APOA4 \\
\hline
\end{tabular}

1) $\mathrm{GC}$, vitamin D-binding protein precursor; A2M, a-2-macroglobulin; C4, complement C4 precursor; APOA4, apolipoprotein A-IV precursor.

The expression levels shown in Figure 5 were calculated as the ratio among the three groups. All data are shown in Supplementary Table S5. A2M expression was increased (CH/C: 6.10\%) in the $\mathrm{CH}$ group and reduced (SH/C: $15.53 \%$ ) in the SH group. The WB analysis strongly supported the results of 2D-DIGE combined with MALDI-TOF-MS.

\section{DISCUSSION}

In this study, eight types of proteins were found among the three

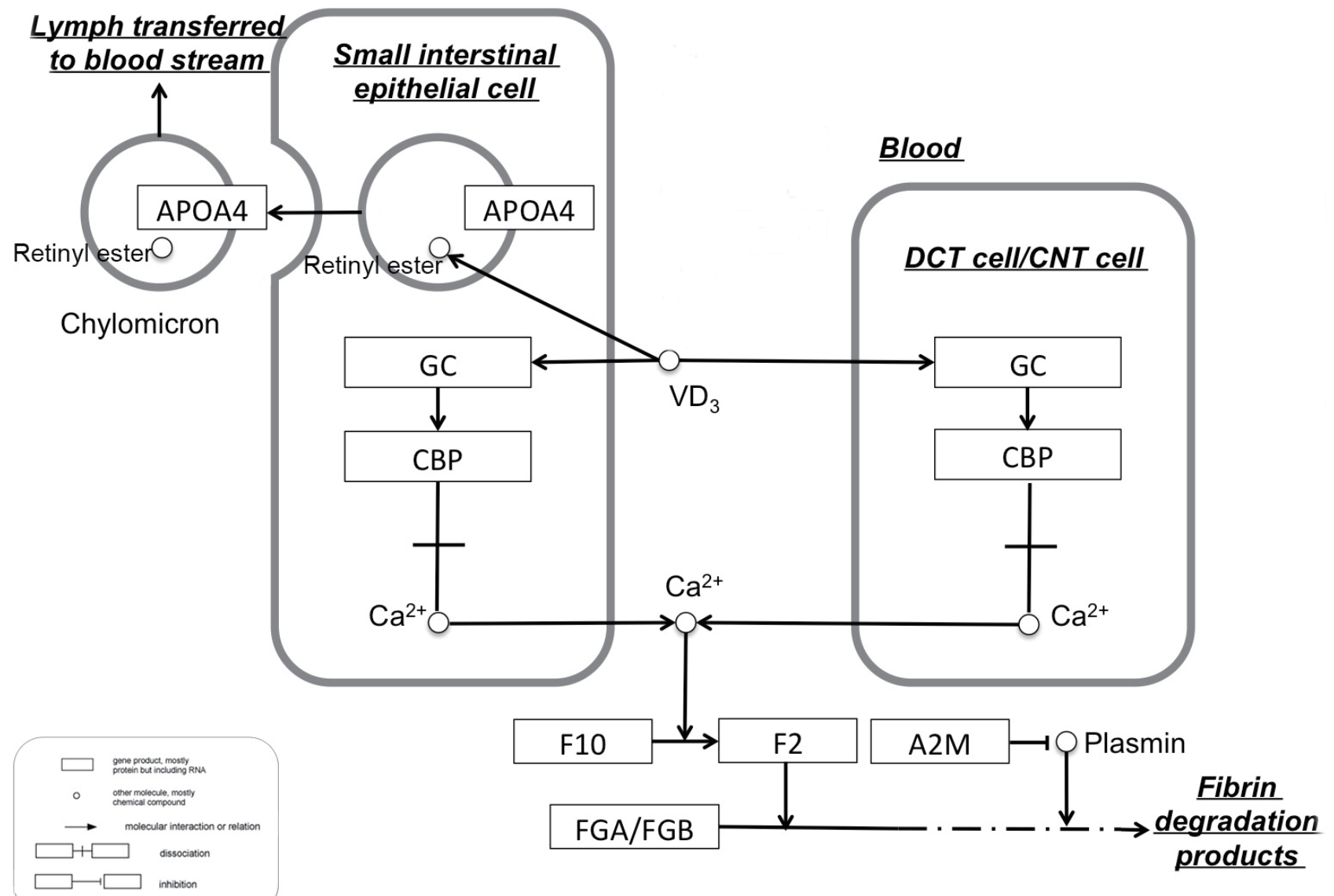

Figure 4. Pathway analysis. This is an integrated pathway to show the relationship between differentially expressed proteins and Ca regulation. The location and physiological process are indicated in italic and underlined font, respectively. APOA4, apolipoprotein A-IV; GC, vitamin D-binding protein; A2M, A2M protein; CBP, calcium binding protein; F2, blood coagulation factor 2; F10, blood coagulation factor 10; FGA, fibrinogen A chain; FGB, fibrinogen B chain. DCT cell, distal convoluted tubular cell; CNT cell, connecting tubular cell. 

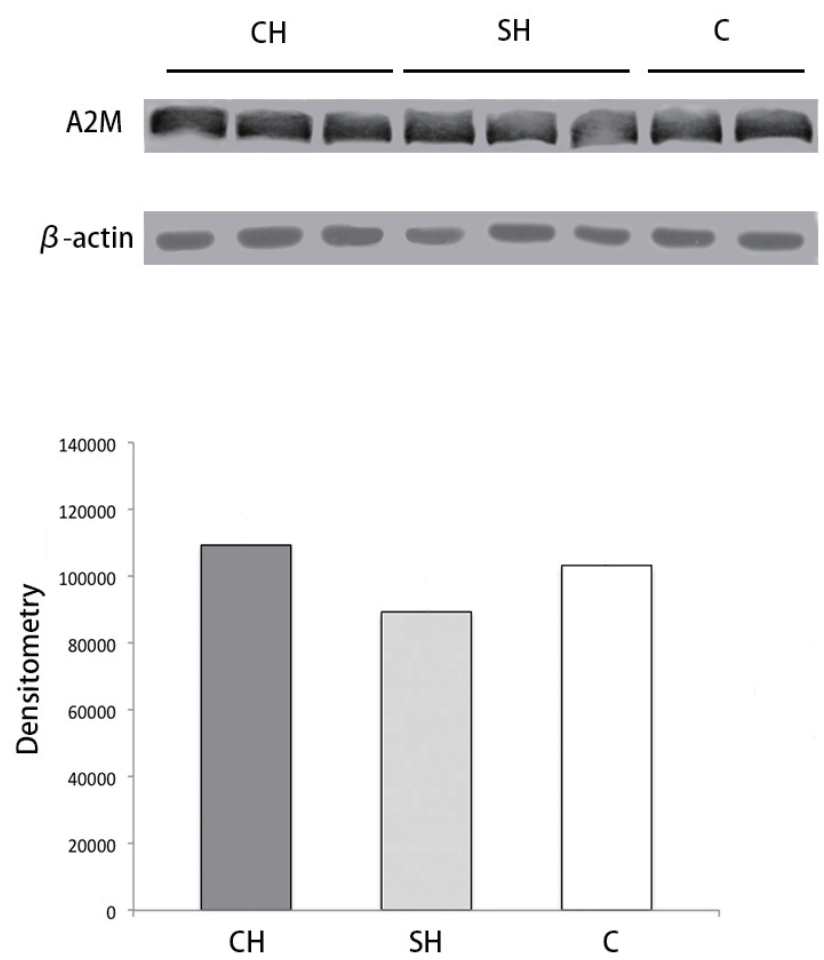

Figure 5. Alpha-2-macroglobulin (A2M) was compared among the three groups for validation by western blot (WB) analysis. Upper figure: Three clinical hypocalcemia (CH) group samples and three subclinical hypocalcemia $(\mathrm{SH})$ group samples were subjected to western blotting analysis of A2M including two normal plasma controls. Lower figure: A2M protein expression in all cows.

groups via 2D-DIGE/MALDI-TOF-MS. Of these, bioinformatics analysis indicated that GC and $\mathrm{A} 2 \mathrm{M}$ were relative to hypocalcemia. A2M was chosen for western blotting analysis based on the results of DIGE/MALDI-TOF-MS and bioinformatics analysis.

\section{Potential pathogenesis of clinical hypocalcemia}

In this study, the serum Ca concentrations of all cattle decreased on day 0 , which was consistent with the results of previous studies $[11,12]$. This decrease likely resulted from providing nutrition to the fetus and formation of the beestings. Mechanisms are in place to efficiently maintain normal serum Ca concentration most of the time, but occasionally these homeostatic mechanisms fail, which results in hypocalcemia [3]. Physiologically, hormones, including calcitonin (decreases Ca concentration), parathyroid hormone (PTH, increases Ca concentration), and 1,25-dihydroxyvitamin $\mathrm{D}_{3}\left(1,25(\mathrm{OH})_{2} \mathrm{D}_{3}\right.$, increases Ca concentration), act to control Ca metabolism [1]. $1,25(\mathrm{OH})_{2} \mathrm{D}_{3}$ is required to stimulate the intestine to absorb dietary $\mathrm{Ca}$. This hormone is produced in the kidney from vitamin $\mathrm{D}$ [13]. About $85 \%$ of serum $1,25(\mathrm{OH})_{2} \mathrm{D}_{3}$ binds with high affinity to GC [14]. GC is a $55-\mathrm{kDa}$ protein that is a member of the albumin superfamily and is secreted by the liver. One of the physiological functions of the GC protein is vitamin D transport and storage [15]. According to the results of this study, GC was down-regulated in the $\mathrm{CH}$ group, as compared with the $\mathrm{C}$ and $\mathrm{SH}$ groups, while there was no significant difference between the $\mathrm{C}$ and $\mathrm{SH}$ groups. As a potential pathogenesis of $\mathrm{CH}, \mathrm{GC}$ was reduced before calving. When the serum $\mathrm{Ca}$ concentration was decreased on calving day, the amount of GC is insufficient to combine with vitamin D. Thus, the role of vitamin D was inhibited leading to a severe decrease in serum Ca concentration. Ca is continually consumed by providing nutrition to the fetus and forming the beestings, which prevents restoration of serum $\mathrm{Ca}$ to normal concentrations.

Another surmise was that APOA4, a $46-\mathrm{kDa}$ high-density lipoprotein (HDL), is secreted from the small intestine in response to lipid absorption and chylomicron formation [16]. It is regulated by leptin, a major component of energy homeostasis [17]. The integrated pathway (Figure 5) shows that ApoA4 enters the circulation on lymph chylomicrons and is subsequently released as a lipid-free protein during lipolysis of chylomicrons [18]. Haas and Mooradian [19] reported that vitamin D levels were positively correlated with plasma HDL levels, but inversely with plasma low-density lipoprotein cholesterol levels. The result of this study showed that APOA4 was down-regulated in the $\mathrm{CH}$ group, as compared with the $\mathrm{C}$ and $\mathrm{SH}$ groups, while there was no significant different between the $\mathrm{C}$ and $\mathrm{SH}$ groups. An addition physiological function of the $\mathrm{GC}$ protein is $\mathrm{VD}_{3}$ storage. In summary, serum APOA4 levels may be affected by Ca regulation and may be positively correlated with GC expression.

\section{Early detection index of hypocalcemia}

In this study, the A2M protein was detected by 2D-DIGE/MALDITOF-MS and verified by WB analysis. A2M expression was up-regulated in the $\mathrm{CH}$ group and down-regulated in the $\mathrm{SH}$ group, as compared with controls. Wang et al [20] reported that $\mathrm{A} 2 \mathrm{M}$ plays a role in osteoarthritis and suggested that $\mathrm{A} 2 \mathrm{M}$ is a powerful inhibitor of many cartilage catabolic factors through protease activities. A2M inhibits cartilage catabolic factor through decreased gene expression to protect the cartilage. In addition, tartrate-resistant acid phosphatase (TRACP) $5 b$ is derived from osteoclasts, which circulate in large complexes that contain A2M and $\mathrm{Ca}$ [21]. Many reports have suggested that serum TRACP $5 \mathrm{~b}$ is a specific and sensitive marker of bone restoration that can be used for the diagnosis and follow-up of skeletal pathologies [22]. Bone-resorbing osteoclasts contain high amounts of TRACP $5 \mathrm{~b}$ and secrete it into the bloodstream.

This evidence suggests that A2M expression is related to $\mathrm{Ca}$ concentration. Although the relationship between $\mathrm{A} 2 \mathrm{M}$ and $\mathrm{Ca}$ remains unclear, $\mathrm{A} 2 \mathrm{M}$ was useful as an early detection index to distinguish $\mathrm{CH}$ from $\mathrm{SH}$ from healthy dairy cows before calving. However, further studies are needed to elucidate the underlying mechanisms.

\section{Other proteins related to hypocalcemia}

Other proteins identified in this study included PON1, C4, HP, 
EN1, and AAT. PON1 is a 44-kDa glycoprotein that hydrolyzes organophosphates found in pesticides, neurotoxins, and arylesters $[22,23]$. PON1 is synthesized mainly in the liver, with lower expression found in the lungs, heart, brain, kidneys, and small intestine [24]. The results of 2D-DIGE/MALDI-TOF-MS showed that $\mathrm{PON} 1$ expression was down-regulated in the $\mathrm{CH}$ group, as compared with the $\mathrm{SH}$ and $\mathrm{C}$ groups, respectively. A possible mechanism for the effects of PON1 is the up-regulation of PTH receptor 1, as described by Lu et al [25]. PTH is an important hormone for the balance of $\mathrm{Ca}$ and $\mathrm{P}$. Since the PTH receptor 1 specifically binds to PTH, the level of PTH receptor 1 is positively correlated with the level of PTH, suggesting that PON1 affects serum Ca concentration via the PON1 receptor 1 and available PTH.

C4 activation acts as immune surveillance system in healthy and altered host cells to detect the presence of foreign matter. $\mathrm{C} 4$ is a component of $\mathrm{C} 3$ convertase in the classical and lectin complement pathways, which is expressed in two polymorphic isotypes, C4A and C4B [26].

$\mathrm{HP}$ is primarily produced in the liver and is functionally important for binding free hemoglobin from lysed red cells in, preventing its toxic effects [27]. Decreased HP is a marker of hemolysis, as HP levels become depleted in the presence of large amounts of free hemoglobin [28].

EN1 is present in endorine tissues, as specified by "endo" and its serpin-like characteristic indicated by "pin", thus designating this new serpin as endopin 1. EN1 is present within isolated chromaffin granules, secreted from chromaffin cells in culture, and inhibits trypsin and plasmin via cleavage at basic residues [29].

$\mathrm{AAT}$ is a $52-\mathrm{kD}$ glycoprotein produced mainly by hepatocytes and secreted into the blood. AAT deficiency is a rare genetic disorder associated with the development of liver and lung diseases [30].

In summary, the results of this study identified several proteins associated with hypocalcemia, although this evidence could also explain other diseases that often occur during and after calving caused by hypocalcemia, including fatty liver (AAT, C4) and endometritis (HP, C4).

In this study, 2D-DIGE/MALDI-TOF-MS, bioinformatics, and western blotting were performed to distinguish healthy cows from those with $\mathrm{CH}$ and $\mathrm{SH}$. A total of eight differentially expressed proteins were identified among the three groups. Due to its specific expression, A2M was selected for validation, and results show that it was as an early detection index. The possible pathogenesis of $\mathrm{CH}$ caused by GC and APOA4 was speculated. Further evaluation of these findings is required for clinical translation.

\section{CONFLICT OF INTEREST}

We certify that there is no conflict of interest with any financial organization regarding the material discussed in the manuscript.

\section{ACKNOWLEDGMENTS}

The authors thank the Beijing Proteome Research Center for providing technological services and International Science Editing for editing of this article. This study was supported by grants from the National Science and Technology Foundation of China (30972235) and Heilongjiang Province Nature Science and Technology Foundation of China (C200916), the Chinese National Science and Technology Project of China (2013BAD21B01-2), and Heilongiiang Bayi Agriculture University graduate student innovation fund project (YJSCX2015-Z03).

\section{REFERENCES}

1.DeGaris PJ, Lean IJ. Milk fever in dairy cows: A review of pathophysiology and control principles. Vet J 2008;176:58-69.

2.Kimura K, Reinhardt TA, Goff JP. Parturition and hypocalcemia blunts calcium signals in immune cells of dairy cattle. J Dairy Sci 2006;89: 2588-95.

3.Goff JP. The monitoring, prevention, and treatment of milk fever and subclinical hypocalcemia in dairy cows. Vet J 2008;176:50-7.

4.Shu S, Xia C, Zhang H, et al. Plasma proteomics analysis of dairy cows with milk fever using SELDI-TOF-MS. Asian J Anim Vet Adv 2014;9: $1-12$.

5.Wang PX, Shu S, Xia C, et al. Protein expression in dairy cows with and without subclinical hypocalcaemia. N Z Vet J 2016;64:101-6.

6.Liu W, Ma Y, Huang L, et al. Identification of HSP27 as a potential tumor marker for colorectal cancer by the two-dimensional polyacrylamide gel electrophoresis. Mol Biol Rep 2010;37:3207-16.

7.Kang G, Li G, Ma H, Wang C, Guo T. Proteomic analysis on the leaves of TaBTF3 gene virus-induced silenced wheat plants may reveal its regulatory mechanism. J Proteomics 2013;83:130-43.

8.Jorrín JV, Maldonado AM, Castillejo MA. Plant proteome analysis: A 2006 update. Proteomics 2007;7:2947-62.

9.Unlü M, Morgan ME, Minden JS. Difference gel electrophoresis: a single gel method for detecting changes in protein extracts. Electrophoresis 1997;18:2071-7.

10. Tonge R, Shaw J, Middleton B, et al. Validation and development of fluorescence two-dimensional differential gel electrophoresis proteomics technology. Proteomics 2001;1:377-96.

11. Bauman DE, Currie WB. Partitioning of nutrients during pregnancy and lactation: A review of mechanisms involving homeostasis and homeorhesis. J Dairy Sci 1980;63:1514-29.

12. Thilsing-Hansen T, Jørgensen RJ, Østergaard S. Milk fever control principles: a review. Acta Vet Scand 2002;43:1-19.

13. Ebert R, Schütze N, Adamski J, Jakob F. Vitamin D signaling is modulated on multiple levels in health and disease. Mol Cell Endocrinol 2006;248:149-59.

14. White $\mathrm{P}$, Cooke $\mathrm{N}$. The multifunctional properties and characteristics of vitamin d-binding protein. Trends Endocrinol Metab 2000;11:320-7.

15. Nagasawa H, Uto Y, Sasaki H, et al. Gc protein (vitamin D-binding protein): Gc genotyping and GcMAF precursor activity. Anticancer 
Res 2005;25:3689-95.

16. Kohan AB, Wang F, Li X, et al. Apolipoprotein A-IV regulates chylomicron metabolism-mechanism and function. Am J Physiol Gastrointest Liver Physiol 2012;302:G628-G36.

17. Doi T, Liu M, Seeley RJ, Woods SC, Tso P. Effect of leptin on intestinal apolipoprotein AIV in response to lipid feeding. Am J Physiol Regul Integr Comp Physiol 2001;281:R753-R9.

18. Weinberg RB, Cook VR, Delozier JA, Shelness GS. Dynamic interfacial properties of human apolipoproteins A-IV and B-17 at the air/water and oil/water interface. J Lipid Res 2000;41:1419-27.

19. Haas MJ, Mooradian AD. What evidence is there for the role of vitamin D and apoA-1 in atheroprotection? Clin Lipidol 2012;7:255-7.

20. Wang S, Wei X, Zhou J, et al. Identification of $\alpha 2$-macroglobulin as a master inhibitor of cartilage-degrading factors that attenuates the progression of posttraumatic osteoarthritis. Arthritis Rheumatol 2014;66:1843-53.

21. Ylipahkala H, Halleen JM, Kaija H, Vihko P, Väänänen HK. Tartrateresistant acid phosphatase $5 \mathrm{~B}$ circulates in human serum in complex with a 2-macroglobulin and calcium. Biochem Biophys Res Commun 2003;308:320-4.

22. Hong SH, Song J, Min WK, Kim JQ. Genetic variations of the paraoxonase gene in patients with coronary artery disease. Clin Biochem 2001;34:475-81.
23. Mackness MI, Arrol S, Abbott C, Durrington PN. Protection of lowdensity lipoprotein against oxidative modification by high-density lipoprotein associated paraoxonase. Atherosclerosis 1993;104:129-35.

24. Primo-Parmo SL, Sorenson RC, Teiber J, La Du BN. The human serum paraoxonase/arylesterase gene ( $P O N 1)$ is one member of a multigene family. Genomics 1996;33:498-507.

25. Lu J, Cheng H, Atti E, et al. Role of paraoxonase-1 in bone anabolic effects of parathyroid hormone in hyperlipidemic mice. Biochem Biophys Res Commun 2013;431:19-24.

26. Paakkanen R, Wennerström A, Liesmaa I, et al. 205-P Immunogenetics of complement C4 deficiencies. Hum Immunol 2011;72:S144.

27. Shih AW, McFarlane A, Verhovsek M. Haptoglobin testing in hemolysis: measurement and interpretation. Am J Hematol 2014;89:443-7.

28. Nielsen MJ, Moestrup SK. Receptor targeting of hemoglobin mediated by the haptoglobins: roles beyond heme scavenging. Blood 2009;114: 764-71.

29. Hwang S-R, Steineckert B, Yasothornsrikul S, et al. Molecular cloning of endopin 1, a novel serpin localized to neurosecretory vesicles of chromaffin cells. Inhibition of Basic Residue-Cleaving Proteases by Endopin 1. J Biol Chem 1999;274:34164-73.

30. Silverman EK, Sandhaus RA. Alpha1-antitrypsin deficiency. New Engl J Med 2009;360:2749-57. 